\section{A Critical Evaluation of Dead Sea Therapy in the Manage- ment of Psoriasis}

\author{
Shirley Telles*, Sachin Kumar Sharma, Savita Agnihotri and \\ Acharya Balkrishna
}

Patanjali Research Foundation, Haridwar, India

\begin{abstract}
Psoriasis is characterized by pronounced proliferation of keratinocytes and vascular inflammatory changes. With conventional treatments having undesirable side-effects there is an interest in other therapies. In particular Dead Sea (DS) balneotherapy and climatotherapy have been useful. The DS is unique in its chemical, climatic and environmental conditions. The combination of chemicals in the DS water, high temperature and other environmental factors appear to induce cell proliferation, reduce inflammation, cause favorable immunomodulation, and selectively protect the patients from harmful Ultraviolet (UV) rays. There may also be psychological benefits of being in proximity to the DS which is historically known to be healing. Despite these benefits it must be noted that DS therapy is contraindicated in certain conditions (e.g., epilepsy) and ineffective in certain types of psoriasis (e.g., pustular). In this article possible mechanisms underlying the benefits and contraindications of Dead Sea balneotherapy and climatotherapy are discussed.

Keywords: Dead Sea therapy; Psoriasis; Underlying mechanisms
\end{abstract}

\section{Introduction}

Psoriasis is an inflammatory, autoimmune disease mediated by interleukin (IL)-17 producing Cluster of Differentiation $4\left(\mathrm{CD} 4^{+}\right)$and $\mathrm{T}$ helper cells (Th) cells [1]. A pronounced proliferation of keratinocytes and of dermal vascular endothelial cells follows the inflammatory response [1]. Conventional treatments are generally immunosuppressant and their long term use is complicated by toxic effects [2]. With this background there is an attempt to seek non-conventional remedies for psoriasis. In this article possible mechanisms underlying the benefits and contraindications of the (i) balneotherapy (chemical and thermal effects) and (ii) climatotherapy (thermal and phototherapy effects) are discussed.

The benefits of DS therapy in patients with psoriasis were determined from a systematic review of articles cited in Medline under the

${ }^{*}$ Corresponding author: Shirley Telles, Patanjali Research Foundation, Patanjali Yogpeeth, Maharishi Dayanand Gram, Near Bahadarabad, Haridwar 249405, Uttarakhand, India, Tel: +91 133424008; E-mail: shirleytelles@gmail.com

Citation: Telles S, Sharma SK, Agnihotri A, Balkrishna A (2017) A Critical Evaluation of Dead Sea Therapy in the Management of Psoriasis. J Altern Complement Integr Med 3: 033.

Received: January 19, 2017; Accepted: June 23, 2017; Published: July 10, 2017 search words 'Dead Sea' (with 360 articles retrieved) [3]. The articles were graded based on the level of evidence [4]. There is evidence based on a single Randomized Controlled Trial (RCT) and a well designed non-randomized controlled trial, that DS water balneotherapy together with DS phototherapy is an effective treatment for psoriasis.

\section{Balneotherapy}

The practice of immersing a participant in mineral water, or mineral-laden mud is known as Balneotherapy. It has been used using water specifically from the DS in the treatment of psoriasis [5]. The DS is the deepest, most saline lake on earth which is estimated to be 50,000 years old [6]. The salt concentration is about 7 to 10 times that of the oceans [7]. Apart from $\mathrm{NaCl}$ the DS spring water contains salts like $\mathrm{MgCl}_{2}, \mathrm{CaCl}_{2}, \mathrm{KCl}$ and $\mathrm{MgBr}_{2}$.

\section{Chemical effects of Balneotherapy on psoriasis}

Magnesium acts as a rate limiting factor in regulating the balance between cyclic Adenosine Monophosphate (cAMP) and cyclic Guanosine Monophosphate (cGMP), which is of importance as an increase in cyclic GMP has been implicated in excessive cellular proliferation, one of the main problems in psoriasis [8]. Magnesium also inhibits the synthesis of certain polyamines which are involved in psoriasis [9]. Other benefits of magnesium are more mechanical; such as its effects as a natural moisturizer by increasing the ability of skin to retain water [10]. At a cellular level magnesium helps in maturation and differentiation of keratinocytes [10]. Hence the magnesium content of DS water is useful in multiple ways for psoriasis. The topical application of magnesium appears to have no adverse effects.

Apart from this Dead Sea water contains high amount of bromide compounds. Bromide compounds are more powerful than their chloride counterparts and potassium bromide has the strongest inhibitory effect even when compared to magnesium [11]. Magnesium bromide and magnesium chloride had inhibitory effects on proliferation of fibroblasts from psoriatic and healthy skin biopsy specimens [11]. Though bromide has beneficial effects the possibility of toxic effects needs to be examined. For example, the application of bromide compounds was associated with contact dermatitis in guinea pigs [12].

\section{Thermal effects of balneotherapy on psoriasis}

In addition, immuno-modulatory effects of DS balneotherapy were assessed in an experimentally induced psoriasis murine model [13]. Experimental animals were treated with thermo-mineral water. There was a substantial reduction in the lesional mRNA levels of IL$17 \mathrm{~A}$ and IL-23 in the thermo-mineral water treated group. This group also showed a significant reduction in serum levels of IL-4 and IL-5. Normal T cell proportions were also observed. These results in experimental models are supported by results in humans though systematic studies are lacking [14].

\section{Climatotherapy}

Near the DS, the content of selenium is high in the local drinking water. Selenium is an essential trace element. Selenium may be useful in psoriasis because it acts as an antioxidant, anti-inflammatory substance and a protector against Ultraviolet UV-A and UV-B light [15]. 
Despite the benefits, ingestion of selenium has been associated with toxic effects when taken in excess [16]. Nine patients who presented after the intake of a dietary supplement containing selenium which had a formulation error had symptoms of toxicity [16]. The symptoms manifested within a week of ingestion and included alopecia, dystrophic fingernail changes, gastrointestinal symptoms and memory difficulties. None of the nine persons required hospitalization and all were managed with supportive care. It is unlikely, but possible that patients with psoriasis receiving DS therapy would ingest sufficient water for selenium toxicity to occur. It is also worth noting that modest increases of selenium levels in the skin may accelerate the growth of incipient tumors in mice [17].

\section{Thermal effects of climatotherapy on psoriasis}

While the basic pathological condition in psoriasis is increased skin cell proliferation, the inflammatory changes in blood vessels further worsen the condition [1]. Apart from its therapeutic effect the DS is also effective because of its unique environment mainly its high temperature and low humidity [3].

Heat may have immuno-suppressive effects by which humoral and cell meditated immune responses are reduced. Thermal treatment also results in a concurrent unexplained reduction in serum cortisol levels [18].

In summary the DS appears to be uniquely suited to treat skin and rheumatic disease; which has been known since ancient times. The therapeutic benefits can be attributed to multiple factors. These include the unique climatic characteristics and natural resources, DS water with its unparalleled salinity and unique composition, DS mineral mud, increased bromide content of the air and a high selenium content of local drinking water.

\section{Effects of phototherapy on psoriasis}

It is well known that there is a selective therapeutic pattern of the response to the sun's radiation at the DS [19]. UV radiation is attenuated when crossing the extra $420 \mathrm{~m}$ of the atmosphere at DS. In the DS there is a significant attenuation of shorter, erythematous, more deleterious UV-B (280-300 nm), while the larger therapeutic wavelengths (300-320 nm) are mildly attenuated, resulting in an enhancement of the therapeutic to damaging ratio [3]. This decreases the risk of skin damage and skin neoplasia following DS water exposure.

Despite the many benefits of climatotherapy adverse effects such as sunburn ( 5 percent) and photo sensitivity reactions ( 8.5 percent) have been observed in few patients [20]. Apart from this there are general contraindications for using DS climatotherapy which include severe psychiatric conditions, epilepsy, cardiac dysrhythmias, compromised balance and addiction to mind-altering substances e.g., alcohol [21]. While most kinds of psoriasis respond to the DS therapy, the exceptions are generalized pustular psoriasis and erythoderma [22].

\section{Summary}

Diverse mechanisms may explain the benefits of DS therapy $[23,24]$. These include mechanical, thermal and chemical effects. The chemical effects of DS therapy have been supported by in vivo and in vitro studies which show increased levels of minerals influencing cell proliferation and differentiation [8,25-27]. Anti-inflammatory and immuno-modulatory effects involve various cell lineages. Also bathing in high concentrated salt solutions can cause the elution of various pro-inflammatory mediators of the skin from patients of psoriasis [28-30]. Another benefit of DS therapy is increased photosensitivity to UV-B irradiation which may contribute to the efficacy of photo-balneotherapy suggesting that the beneficial effect of Dead Sea climatotherapy is greater than balneotherapy alone.

Finally the psychological effect of being in the DS area with its historical significance in healing cannot be overlooked. A major disadvantage of using these reported benefits is that most trials were carried out on animal models with few trials on human patients $[3,5,13,26]$. The number of well designed RCT is small and hence the findings are open to question [3]. There is also a degree of uncertainty about the treatment protocol in terms of the duration and frequency of sun exposure; and similarly the duration and frequency of bathing in the DS [31]. Also despite the fact that the DS high salt and mineral content make it very safe to swim there have been reports of persons drowning in the DS [32]. This is believed to occur if a person trips, falls and swallows water. Swallowing DS water carries other risks as the high sodium content disrupts the body's electrolyte balance.

\section{Future Directions}

Hence though beneficial, adverse effects of DS therapy cannot be entirely ruled out. The focus of future research should be the long term follow-up of patients undergoing DS therapy for psoriasis. All adverse outcomes should be systematically documented.

\section{References}

1. Belge K, Brück J, Ghoreschi K (2014) Advances in treating psoriasis. F1000Prime Rep 6: 4.

2. Rebora A (2007) Conventional therapies for psoriasis. Reumatismo 59: 7780 .

3. Katz U, Shoenfeld Y, Zakin V, Sherer Y, Sukenik S (2012) Scientific evidence of the therapeutic effects of dead sea treatments: a systematic review. Semin Arthritis Rheum 42: 186-200.

4. Hunt SA, Baker DW, Chin MH, Cinquegrani MP, Feldman AM, et al. (2001) ACC/AHA Guidelines for the Evaluation and Management of Chronic Heart Failure in the Adult: Executive Summary A Report of the American College of Cardiology/American Heart Association Task Force on Practice Guidelines (Committee to Revise the 1995 Guidelines for the Evaluation and Management of Heart Failure): Developed in Collaboration With the International Society for Heart and Lung Transplantation; Endorsed by the Heart Failure Society of America. Circulation 104: 2996-3007.

5. Roos S, Hammes S, Ockenfels HM (2010) [Psoriasis. Natural versus artificial balneophototherapy]. Hautarzt 61: 683-690.

6. Schamberg IL (1978) Treatment of psoriasis at the Dead Sea. Int J Dermatol 17: 524-525.

7. Even-Paz Z, Shani J (1989) The Dead Sea and psoriasis. Historical and geographic background. Int J Dermatol 28: 1-9.

8. Voorhees JJ, Duell EA (1975) Imbalanced cyclic AMP-cyclic GMP levels in psoriasis. Adv Cyclic Nucleotide Res 5: 735-758.

9. Lowe NJ, Breeding J, Russell D (1982) Cutaneous polyamines in psoriasis. $\mathrm{Br} J$ Dermatol 107: 21-25.

10. Riyaz N, Arakkal FR (2011) Spa therapy in dermatology. Indian J Dermatol Venereol Leprol 77: 128-134.

11. Levi-Schaffer F, Shani J, Politi Y, Rubinchik E, Brenner S (1996) Inhibition of proliferation of psoriatic and healthy fibroblasts in cell culture by selected Dead-sea salts. Pharmacology 52: 321-328.

12. Harris GL, Maibach HI (1989) Allergic contact dermatitis potential of 3 pyridostigmine bromide transdermal drug delivery formulations. Contact Dermatitis 21: 189-193. 
Citation: Telles S, Sharma SK, Agnihotri A, Balkrishna A (2017) A Critical Evaluation of Dead Sea Therapy in the Management of Psoriasis. J Altern Complement Integr Med 3: 033.

13. Lee YB, Lee JY, Lee HJ, Yun ST, Lee JT, et al. (2014) Immunomodulatory effects of balneotherapy with hae-un-dae thermal water on imiquimod-induced psoriasis-like murine model. Ann Dermatol 26: 221-230.

14. Sukenik S, Abu-Shakra M, Flusser D (1997) Balneotherapy in autoimmune disease. Isr J Med Sci 33: 258-261.

15. Moysan A, Morlière $P$, Marquis I, Richard A, Dubertret L (1995) Effects of selenium on UVA-induced lipid peroxidation in cultured human skin fibroblasts. Skin Pharmacol 8: 139-148.

16. Aldosary BM, Sutter ME, Schwartz M, Morgan BW (2012) Case series of selenium toxicity from a nutritional supplement. Clin Toxicol (Phila) 50: 57-64.

17. Cassidy PB, Fain HD, Cassidy JP Jr, Tran SM, Moos PJ, et al. (2013) Selenium for the prevention of cutaneous melanoma. Nutrients 5: 725-749.

18. Cozzi F, Lazzarin P, Todesco S, Cima L (1995) Hypothalamic-pituitary-adrenal axis dysregulation in healthy subjects undergoing mud-bath applications. Arthritis Rheum 38: 724-725.

19. Abels DJ, Kattan-Byron J (1985) Psoriasis treatment at the Dead Sea: a natural selective ultraviolet phototherapy. J Am Acad Dermatol 12: 639-643.

20. Shani J, Seidl V, Hristakieva E, Stanimirovic A, Burdo A, et al. (1997) Indications, contraindications and possible side-effects of climatotherapy at the Dead-Sea. Int J Dermatol 36: 481-492.

21. Halevy S, Sukenik S (1998) Different modalities of spa therapy for skin diseases at the Dead Sea area. Arch Dermatol 134: 1416-1420.

22. Matz H, Orion E, Wolf $\mathrm{R}$ (2003) Balneotherapy in dermatology. Dermatol Ther 16: $132-140$
23. Lotti T, Freedman D (1994) Balneology and spa treatments in dermatology: the European point of view. J Eur Acad Dermatol Venereol 3: 449-450

24. Tishler M, Shoenfeld $Y$ (1996) The medical and scientific aspects of spa therapy. Isr J Med Sci 32: 8-10.

25. Blondell JM (1980) The anticarcinogenic effect of magnesium. Med Hypotheses 6: 863-871.

26. Shani J, Barak S, Levi D, Ram M, Schachner ER, et al. (1985) Skin penetration of minerals in psoriatics and guinea-pigs bathing in hypertonic salt solutions. Pharmacol Res Commun 17: 501-512.

27. Shani J, Sharon R, Koren R, Even-Paz Z (1987) Effect of Dead-Sea brine and its main salts on cell growth in culture. Pharmacology $35: 339-347$.

28. Valitutti S, Castellino F, Musiani P (1990) Effect of sulfurous (thermal) water on T lymphocyte proliferative response. Ann Allergy 65: 463-468.

29. Simonelli C (1994) Come le acque sulfuree modulano il sistema immunitario. Current 1:15

30. Wollenberg A, Richard A, Bieber T (1992) In vitro effect of the thermal water from La Roche-Possay on the stimulatory capacity of epidermal Langerhans cells. Eur J Dermatol 2: 128-129.

31. Kushelevsky AP, Slifkin MA (1975) Ultraviolet measurements at the Dead Sea and at Beersheba. Isr J Med Sci 11: 488-490.

32. Even D (2010) Think That Swimming in Dead Sea Is Safe? Think Again. Hartez, Israel. 